\title{
Radiological signs of ulcerative colitis: assessment of their reliability by means of observer variation studies
}

\author{
N. GEFFEN, A. DARNBOROUGH, F. T. de DOMBAL, G. WATKINSON, \\ AND J. C. GOLIGHER ${ }^{1}$ \\ From the Colitis Clinic of the Professorial Surgical Unit, and the Diagnostic \\ $X$-ray Department, The General Infirmary at Leeds
}

Since the radiological appearances of ulcerative colitis were described in 1912 by Stierlin, these appearances have evoked much investigation and speculation. Many and varied radiological signs are described as typical of ulcerative colitis and yet very few workers have attempted to analyse these signs in any detail in order to determine their reliability, usefulness, and prognostic significance to the patient. It therefore seems to us particularly relevant to examine our own experience in this field in a highly critical manner.

Our investigations have been divided into three parts. We have carried out preliminary observer variation studies in order to determine the reliability of each individual radiological sign. Next we have subjected those of the signs which were found to be reliable to further analysis by a correlation with the clinical state and prognosis of the patient. And finally we have investigated the change in the extent of colitis which has taken place in our patients over a period of years.

In this report we shall describe the results of our initial studies, namely, those involving observer variation.

\section{MATERIAL AND METHODS}

OBSERVER VARIATION STUDIES The films from a single barium enema examination in each of 20 patients were selected at random. All patients were diagnosed as suffering from ulcerative colitis, on clinical, sigmoidoscopic, and radiological grounds, and the diagnosis was confirmed in many of these 20 patients when they later came to surgery.

The films were then examined by two radiologists (N.G. and A.D.) each of whom inspected the films and recorded his findings independently; neither radiologist

${ }^{1}$ Address for reprints: Prof. J. C. Goligher, University Department of Surgery, The General Infirmary at Leeds. was aware of any clinical details. The colon was divided into four areas, or 'segments', in a manner shown in Fig. 1, these segments being $(a)$ the caecum and ascending colon, $(b)$ the transverse colon, $(c)$ the descending colon, and $(d)$ the rectum and sigmoid colon. Thus 80 segments of colon were available for examination.

The two radiologists both examined the 'filled film' (the film taken after barium had been run into the colon), and the 'post-evacuation' film (taken after the patient had evacuated the barium). In each of the 80 segments the presence or absence of the various signs of ulcerative colitis was noted, and a detailed comparison was subsequently made between the findings of each radiologist, to determine the extent of observer agreement in the case of each individual sign.

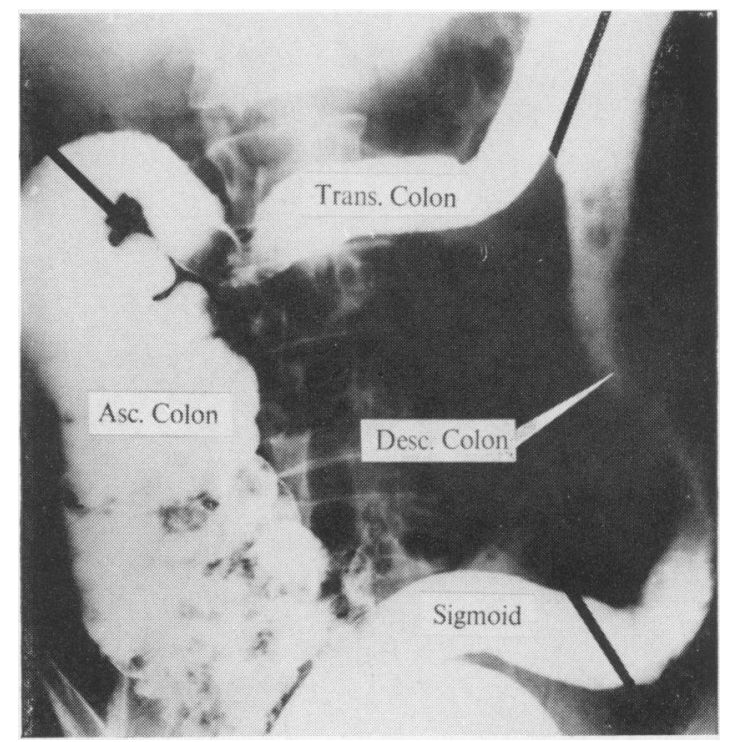

FIG. 1. Barium enema showing division of colon into four 'segments' for purposes of evaluation. 


\section{DEFINITION OF TERMS}

The radiological signs which were investigated are listed in Tables I, II, and III. These tables also indicate the number of segments in which agreement was reached concerning the presence or absence of each sign, together with the number of segments where the two radiologists failed to reach such agreement.

In three of the $\mathbf{8 0}$ segments (in each case the ascending colon), both observers agreed that the filled film was of

\section{TABLE I}

RADIOLOGICAL SIGNS INVESTIGATED ON FILLED FILM TOGETHER WITH THEIR INCIDENCE AND OBSERVER VARIATION

\begin{tabular}{lcrl} 
Sign & \multicolumn{3}{c}{ Number of Segments } \\
\cline { 2 - 4 } & Present $^{\mathbf{1}}$ & Disagreed & Absent $^{2}$ \\
\hline Absent haustration & 45 & 7 & 25 \\
Smooth contour & 23 & 16 & 38 \\
Ulceration & 18 & 8 & 51 \\
Coarse serration & 10 & 13 & 54 \\
Swollen mucosa & 9 & 11 & 57 \\
Fine serration & 9 & 4 & 64 \\
Double contour & 7 & 3 & 67 \\
Pseudopolyps & 5 & 2 & 70 \\
Faecal residue & 5 & 9 & 63 \\
Spiculation & 3 & 2 & 72 \\
Corrugation & 0 & 6 & 71 \\
Indenture & 0 & 5 & 72 \\
Longitudinal furrowing & 0 & 5 & 72 \\
Eccentric contour & 0 & 3 & 74 \\
Differential involvement & 0 & 2 & 75
\end{tabular}

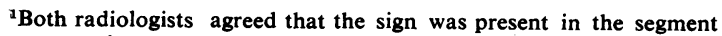
concerned.

${ }^{2}$ Both radiologists agreed that the sign was absent in the segment concerned.

TABLE II

RADIOLOGICAL SIGNS INVESTIGATED ON POST-EVACUATION FILM TOGETHER WITH THEIR INCIDENCE AND OBSERVER VARIATION

Number of Segments

\begin{tabular}{llcl} 
& \multicolumn{3}{c}{ Number of Segments } \\
\cline { 2 - 4 } & Present & Disagreed & Absent \\
\hline Abnormal haustra & 35 & 5 & 18 \\
Longitudinal folds & 15 & 5 & 38 \\
Polyps & 9 & 4 & 45 \\
Ulceration & 5 & 4 & 49 \\
Honeycomb pattern & 4 & 5 & 49 \\
Coarse transverse folds & 1 & 5 & 52 \\
Reticular pattern & 0 & 10 & 48
\end{tabular}

TAB LE III

GENERAL RADIOLOGICAL SIGNS INVESTIGATED TOGETHER WITH THEIR INCIDENCE AND OBSERVER VARIATION

Number of Segments

\begin{tabular}{llcl} 
& \multicolumn{3}{l}{ Number of Segments } \\
\cline { 2 - 4 } & Present & Disagreed & Absent \\
\hline Decreased calibre & 27 & 10 & 40 \\
Decreased distensibility & 27 & 10 & 40 \\
Decreased length & 23 & 6 & 48 \\
Decreased tone & 17 & 8 & 52
\end{tabular}

such poor quality as to be of no diagnostic value. After evacuation of the barium, a further 12 segments showed no pattern, either due to inadequate evacuation of the barium, or because the coating of the mucosa was too thin. These segments have therefore been excluded from present consideration.

For the purposes of this analysis the criteria for observing each of the radiological signs were strictly defined as follows.

THE FILLED FILM The 'filled film' (the film taken after barium was run into and distended the colon) is of the utmost value in outlining the contour of the bowel. In ulcerative colitis, abnormalities of this contour can appear (Table I). These abnormalities have been defined as follows:-

Absent haustration The normal globular evenlyspaced haustra are lost, and replaced either by a smooth or by a grossly irregular, contour.

Ulceration Two types of ulcers are recognized: (a) small spiky broad-based triangular projections from the contour, and (b) larger ulcers of the "collar stud' variety. These collar stud ulcers are punched out projections from the contour, with a flattened base, and overhanging margins.

Coarse serration A coarsely serrated contour resembles the edge of torn blotting paper. It results in a gross irregularity of contour usually with well defined deep and shallow indentations.

Swollen mucosa Sometimes folds of oedematous mucosa can be identified at the edge of the column of barium. In their most extreme form, these give rise to coarse serrations.

Fine serration A finely serrated contour shows small projections from an otherwise smooth edge. The projections are irregularly spaced and of varying sizes but usually no more than 1 to $3 \mathrm{~mm}$ in depth.

Double contour Sometimes when large ulcers are confluent, they give rise to a continuous track of barium paralleling the bowel contour and connected with the lumen at several points. Such a track varies in length from a few centimetres even up to $30 \mathrm{~cm}$ in some cases.

Pseudopolyps Pseudopolyps present as discrete translucencies of varying sizes seen through the opacity of the barium-filled colon. They are frequently confused with faecal residue.

Faecal residue Small areas of faeces also present as areas of translucency, but these areas may be distinguished from pseudopolyps by their irregular ill-defined, mottled appearance, and their mobility.

Spiculation This term implies the presence of fine, evenly-spaced projections from the contour. Unlike fine serrations, these projections are of equal size, and are usually about one millimetre or less in depth. The sign was first described by Dassel (1962).

Corrugation This is described (Anton and Palmer, 1962 ) as the replacement of normal haustration by a smoothly undulating contour resembling the edge of a sheet of corrugated iron, usually associated with a thickening of the interhaustral bands.

Indenture The 'indenture sign' consists of smooth uniform peaks, spikes, or serrations produced by barium 
extending between swollen mucosal folds as described by Poppel and Berenbaum (1957).

Longitudinal furrowing This appearance on the filled film corresponds with that of coarse longitudinal folds on the post-evacuation film, and will be defined under that heading.

Eccentric contour Normally, in each segment, the colonic contours on either side of the column of barium are symmetrical. Loss of this symmetry is referred to as an 'eccentric contour' in that segment.

Differential involvement Occasionally, in those parts of the colon affected by colitis, there is a wide range of radiological appearances. This situation is referred to as differential involvement.

THE POST-EVACUATION FILM The film taken after the patient had been asked to evacuate the barium also provided useful data. The principal value of the film is that it shows the pattern of the colonic mucosa in many patients; although in some patients the colon is incapable of contraction, in some no evacuation occurs, and in some patients the coating of barium after evacuation is so thin that no mucosal pattern is visible. This state of affairs is called 'effacement' of the mucosal pattern.

Some signs which are visible on the filled film, such as ulcers or pseudopolyps, are also visible on the postevacuation film. Other appearances of the colonic mucosa are as follows:-

Abnormal haustration If evacuation is incomplete, barium sometimes remains in the colon. In such instances, inefficient attempts by the colon to get rid of the barium may result in a pronounced abnormal haustration being visible on the post-evacuation film. In extreme cases, these haustrations resemble a string of sausages.

Coarse transverse or longitudinal folds The normal post-evacuation appearance is of a fine crinkly 'reticular' pattern, with both a transverse and a longitudinal component. Ulcerative colitis may so distort and stretch this pattern that either of these components may completely dominate the radiological picture, giving rise to coarse folds running in either the transverse or longitudinal direction.

Coarse reticular pattern Occasionally it may be impossible to decide which of the components dominates a coarse mucosal pattern; this pattern is then said to be coarsely reticular.

Honeycomb pattern A post-evacuation pattern of the colonic mucosa is sometimes seen which resembles cobblestones or a honeycomb, with a thin layer of barium outlining many interlocking translucent areas. Because of its obvious resemblance this pattern is called a honeycomb pattern.

GENERAL SIGNS Certain important general signs were noted both on the filled film and after evacuation, which could not be classified as contour abnormalities of the mucosal pattern. These signs were:-

Decreased calibre The whole colon (or segment) was uniformly of smaller calibre than normal but this term was not applied to localized areas of narrowing or strictures.
Decreased distensibility This term was applied when the column of barium was unable to distend the colon in the normal fashion.

Decreased length The colon appeared shorter than could be accounted for by the normal variation between individuals. This sign was most easy to interpret in cases where part of the colon was involved.

Decreased tone This sign was present if the colon was unable to contract when the patient was asked to evacuate the barium. It was usually associated with retention of a substantial amount of barium, and a poor mucosal pattern on the post-evacuation film.

\section{RESULTS}

Two aspects of our data are immediately apparent. There was no instance of complete agreement between the two observers on the presence or absence of any one radiological sign; and in addition, many of these signs were only recorded on a few occasions. Therefore, for the purpose of evaluating these data we have divided the signs into four groups according to their agreed incidence (the number of segments in which both observers agreed their presence) and observer variation (Tables IV-VII).

The first group of signs (Table IV) were both frequent and reliable. The agreed incidence in each case was over $10 \%$, and the observer variation was low, usually around $7 \%$, and in all cases being less than half the agreed incidence. In each case this degree of observer agreement was significant $(P<0.01)$, but the value of statistical analysis in this situation is somewhat doubtful, due to the large number of normal segments.

T A B LE IV

FREQUENT AND RELIABLE SIGNS ${ }^{1}$

\begin{tabular}{lcr} 
Sign & $\begin{array}{c}\text { Agreed } \\
\text { Incidence } \\
(\%)\end{array}$ & $\begin{array}{c}\text { Observer } \\
\text { Variation } \\
(\%)\end{array}$ \\
\hline Abnormal haustration on post-evacuation & & \\
$\quad$ film & 60.3 & 8.6 \\
Abnormal or absent haustration on filled & & \\
$\quad$ film & $58 \cdot 5$ & $9 \cdot 1$ \\
Decreased calibre & $35 \cdot 1$ & 12.9 \\
Decreased distensibility & $35 \cdot 1$ & 12.9 \\
Decreased length & 29.9 & 7.8 \\
Longitudinal folds on post-evacuation film & 25.9 & 8.6 \\
Ulceration on filled film & 24.7 & 10.3 \\
Decreased tone & 22.0 & 10.3 \\
Polyps on post-evacuation film & 15.5 & 6.9 \\
Fine serration & 11.7 & $5 \cdot 2$
\end{tabular}

${ }^{1}$ Agreed incidence over $10 \%$. Observer variation less than half agreed incidence.

The second group of signs (Table V), although reported quite frequently, could scarcely be regarded as reliable, since the degree of observer variation was almost as great as the agreed incidence, or even greater. Indeed in the case of one of these 
signs, coarse serration, the agreed incidence was $12.9 \%$ but the observer variation was no less than $16.9 \%$. The two observers therefore disagreed about the presence or absence of this sign more often than they were able to agree about its presence. We regard all of the signs in this group as being unreliable, and do not propose to analyse them further.

\section{T A B LE V}

FREQUENT BUT UNRELIABLE SIGNS

\begin{tabular}{lcc} 
Sign & $\begin{array}{c}\text { Agreed } \\
\text { Incidence } \\
(\%)\end{array}$ & $\begin{array}{c}\text { Observer } \\
\text { Variation } \\
(\%)\end{array}$ \\
\hline Smooth contour & $29 \cdot 8$ & $20 \cdot 8$ \\
Coarse serration & 12.9 & 16.9 \\
Oedematous mucosa & 11.7 & 14.3
\end{tabular}

There remain the signs which were infrequently seen. In the third group of signs (Table VI) we have included most of those with an agreed incidence of less than $10 \%$. Their relative infrequency has made it particularly difficult to analyse this group of signs; clearly there is considerable observer variation in some of them but the extremely small numbers involved makes the significance of this difficult to evaluate.

T A B L E V I

INFREQUENT SIGNS WITH SOME OBSERVER VARIATION ${ }^{1}$ $\begin{array}{ll}\text { Sign } & \begin{array}{l}\text { Agreed } \\ \text { Incidence }\end{array} \text { Observer } \\ \text { Variation }\end{array}$

\begin{tabular}{lcc} 
& $\begin{array}{c}\text { Incidence } \\
(\%)\end{array}$ & $\begin{array}{c}\text { Variation } \\
(\%)\end{array}$ \\
\hline Double contour & $9 \cdot 1$ & 3.9 \\
Ulcers on post-evacuation film & 8.6 & 6.9 \\
Polyps on filled film & 6.5 & 2.6 \\
Spiculation & 3.9 & 2.6 \\
Honeycomb pattern & 6.9 & 8.6 \\
Faecal residue & 6.5 & 11.7 \\
Coarse transverse folds & $1 \cdot 7$ & 8.6
\end{tabular}

${ }^{1}$ Evaluation difficult due to small numbers.

There were, however, a few signs (Table VII) in this category which were never agreed to be present by both observers. Occasionally one or other of the observers would claim that these signs were seen, but in view of their failure to reach agreement in a single instance we would regard these signs as being completely unreliable.

T A B L E VII

INFREQUENT AND USELESS SIGNS

Signs

\begin{tabular}{cc}
$\begin{array}{l}\text { Agreed } \\
\text { Incidence }\end{array}$ & $\begin{array}{c}\text { Observer } \\
\text { Variation } \\
(\%)\end{array}$ \\
\hline 0 & $2 \cdot 6$ \\
0 & 3.9 \\
0 & $6 \cdot 5$ \\
0 & $6 \cdot 5$ \\
0 & $7 \cdot 8$ \\
0 & 18.3
\end{tabular}

DISCUSSION

It is generally accepted that the findings at any examination or investigation will be subject to some degree of observer variation (Birkelo, Chamberlain, Phelps, Schools, Zacks, and Yerushalmy, 1947; Garland, 1949; Fletcher, 1952; Davies, L. G. 1958; Bull, Couch, Joyce, Marshall, Potts, and Shaw, 1960). However, the alarming feature of our findings was the enormous variation in interpretation of some signs which are regarded as mainstays in the radiological diagnosis of ulcerative colitis. On the basis of our own experience we feel that some of these 'traditional' signs do indeed require further evaluation and assessment.

The signs which we have studied seemed to fall naturally into four groups, those which we have already outlined in Tables IV-VII according to their incidence and degree of observer variation. We have been unable to analyse some of these data by detailed statistical or actuarial methods due to the relative infrequency of some of the signs investigated (Table VI). Unfortunately these signs are precisely those where our own data are most equivocal, so that it is difficult to draw any conclusions about them at all. Some, like double contour, seem to be fairly reliable, whilst others, like a honeycomb pattern, are almost certainly unreliable.

Moreover, this is not a problem which can be solved merely by a larger scale analysis. If the number of segments examined were doubled, the results would still continue to be swamped by the large number of segments which were agreed to be normal. If a selected group of barium films were analysed, in which the incidence of these signs was high, the results would still be invalid, as both observers would then be expecting to see these signs in every other segment. We have therefore chosen to accept our results at face value and we must frankly admit that our studies have not permitted us to make any sort of thorough assessment of these signs, whose value must remain uncertain.

Our studies have nevertheless enabled us to define, with some degree of precision, four groups of signs.

(1) Useful signs which are both frequent, in that they occur in over $10 \%$ of the segments studied, and reliable, in that they were subject to a low observer variation (Table IV).

(2) Signs which were unreliable, so that the two observers were unable to agree on their presence more frequently than they were able to agree about this; and these signs we regard as useless.

(3) Infrequent signs whose incidence is so small 


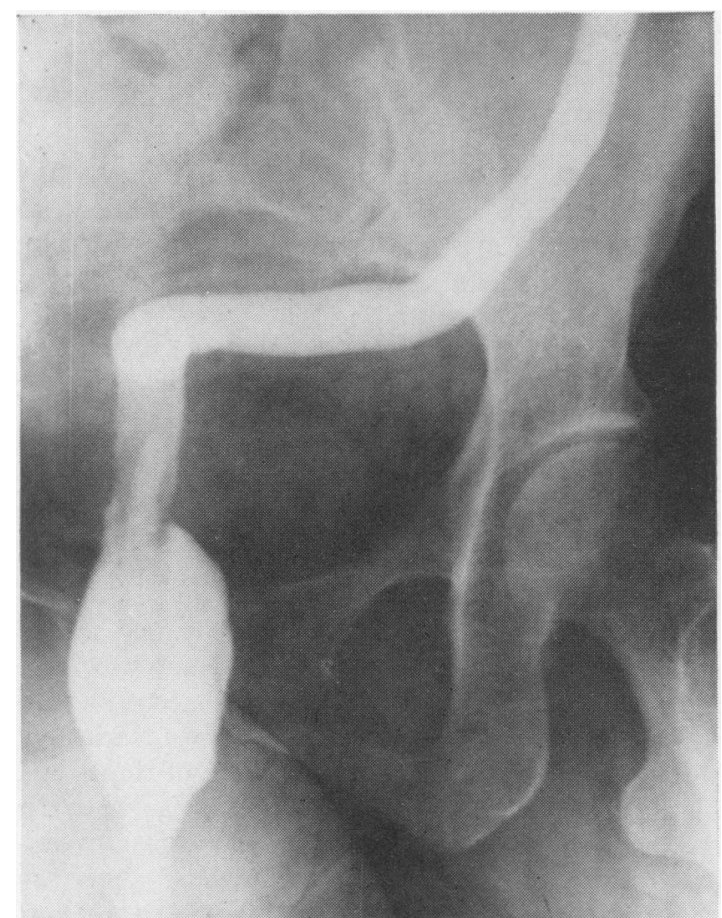

FIG. 2

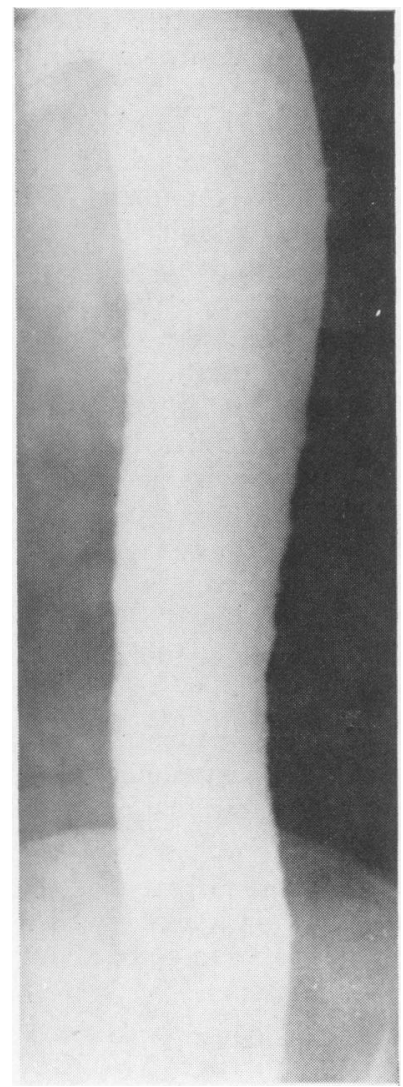

FIG. 2. Filled film of barium enema showing decreased length and calibre of colon, absent haustration, and decreased distensibility.

FIG. 3. Filled film of barium enema showing double contour.

FIG. 4. Filled film of barium enema showing fine serration and ulceration.

FIG. 5. Post-evacuation film after barium enema showing abnormal haustration and longitudinal folds.

FIG. 4

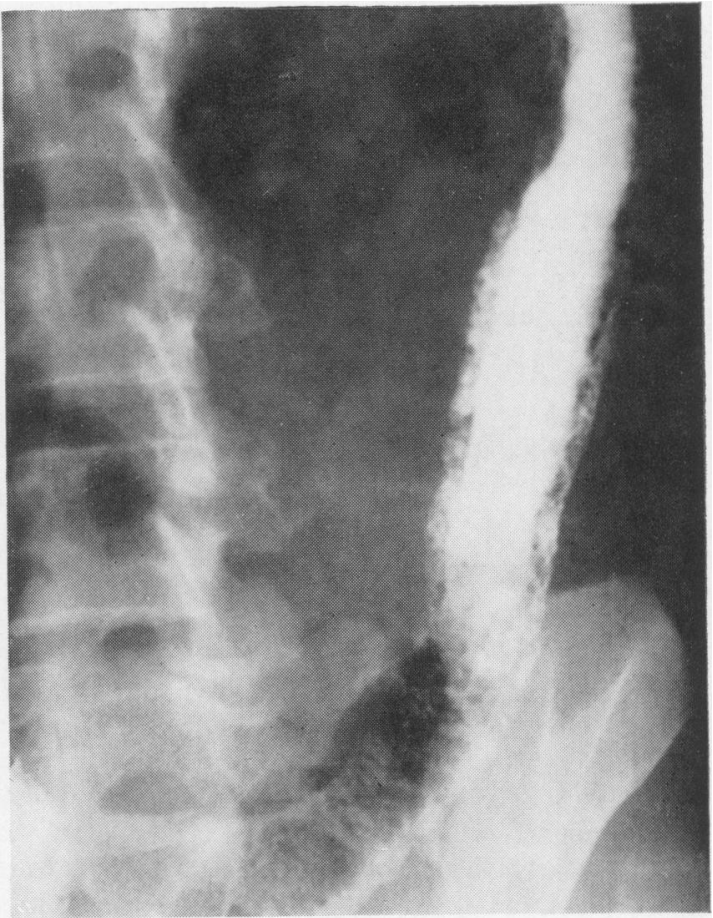

FIG. 3

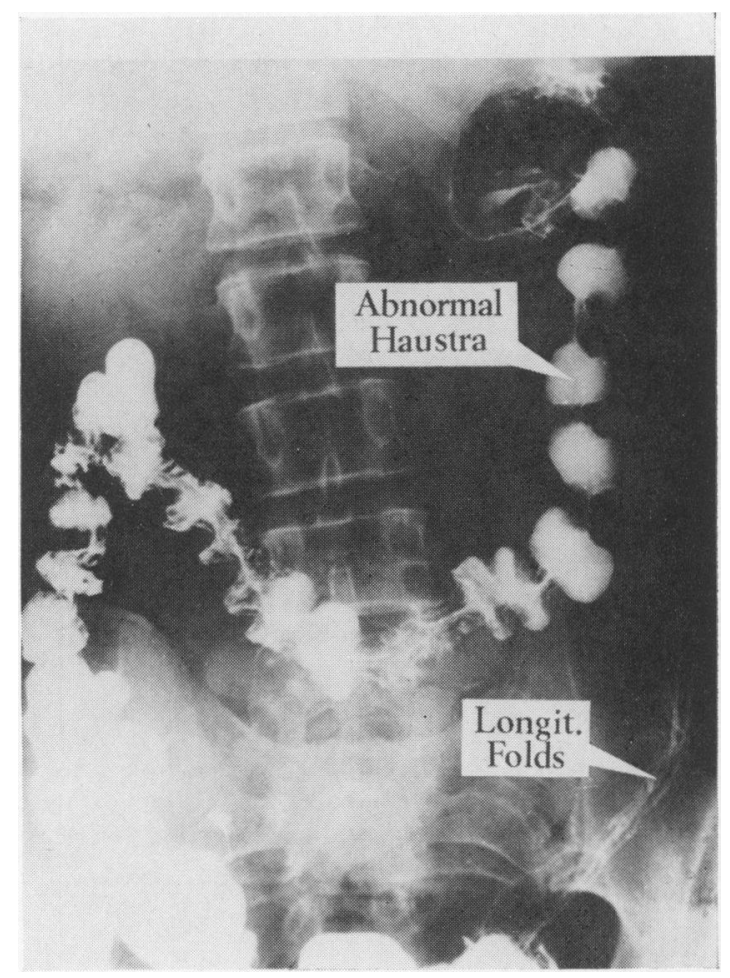

FIG. 5 


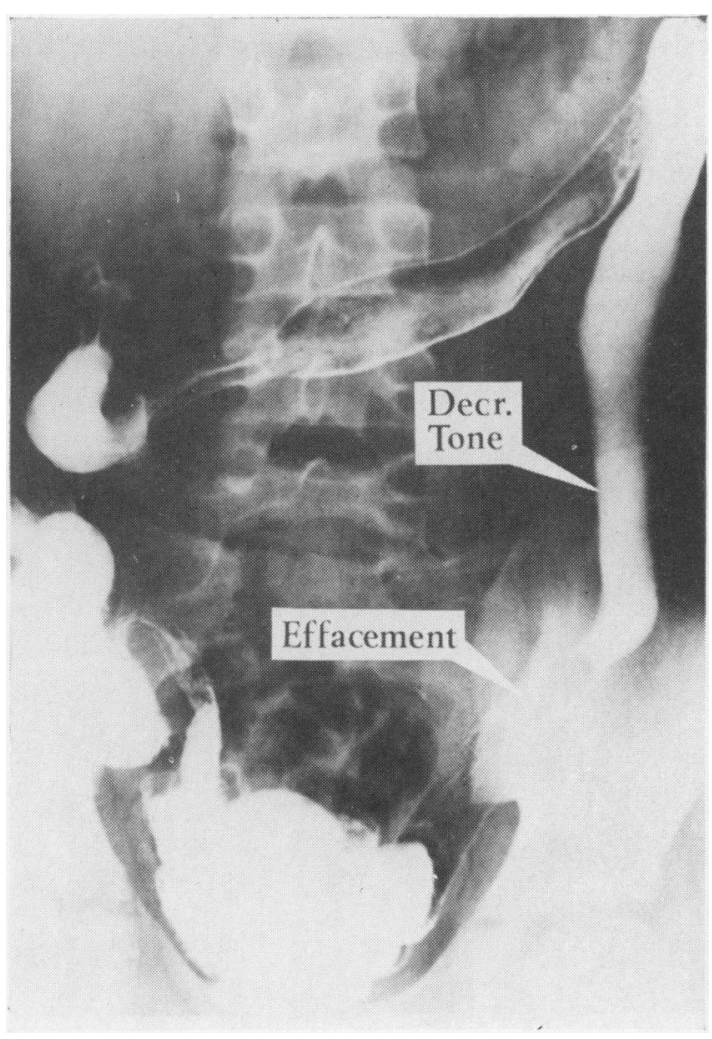

FIG. 6. Post-evacuation film after barium enema showing decreased tone and effacement of mucosa.

that we have been unable to assess them on the basis of this survey.

(4) Signs which the two observers could not agree were present on any occasion, although one or other observer occasionally claimed that these signs were present. We also regard these signs as being of little value.

It is interesting to note that the vast majority of the signs in the useful and reliable group are general signs, such as shortening or narrowing of the colon, and it is perhaps not surprising that there should have been fairly good overall agreement about these relatively well-defined appearances. By contrast, most of the less reliable signs in Table VII are signs reflecting individual opinions, examples of these being the indenture sign of Poppel and Berenbaum and the corrugation sign of Anton and Palmer.

It may well be argued that confusion could have arisen over the terminology used, or that we may have failed to understand the description given by these workers in the literature, but it is precisely

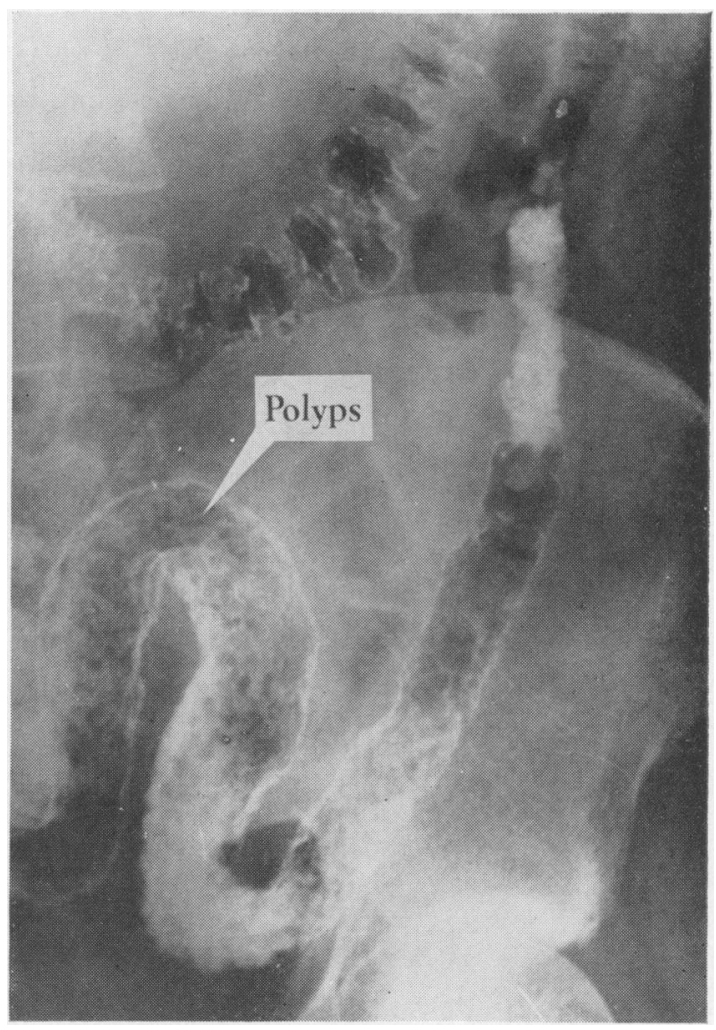

FIG. 7. Post-evacuation film after barium enema showing polyps.

these points which we have tried to assess. If two radiologists with a special interest in the field of colitis, both of whom have read and studied the original descriptions of these signs, cannot agree at all on their presence, then these signs can scarcely be of any use whatsoever from the point of view of the vast majority of radiologists.

We are therefore left, by a process of elimination, with 11 radiological signs (Table IV) which can be relied upon when reported in patients with ulcerative colitis. These signs are illustrated in Figs. 2-7, and to them may possibly be added double contour, which, although rare, is a reliable sign when it occurs.

We would suggest that any diagnosis of ulcerative colitis on radiological grounds should be based on the presence or absence of these signs, which are illustrated in Figures 2-7. Any diagnosis based on other signs should be regarded with suspicion, as other radiological signs, in our experience, are open to considerable variation in their individual interpretation. 


\section{SUMMARY}

This paper presents a highly critical evaluation, by means of observer variation studies, of the radiological signs usually described as being indicative of ulcerative colitis.

There was such a wide measure of variation in the recognition of many of these signs as to render them completely valueless.

It is suggested that the radiological diagnosis of ulcerative colitis should be based only on those signs shown in this study to be capable of being reliably recognized.

\section{REFERENCES}

Anton, H. C., and Palmer, J. H. (1962). Corrugation of the colon. Its significance in ulcerative colitis. Brit. J. Radiol., 35, 762768.
Birkelo, C.C., Chamberlain, W. E., Phelps, P.S., Schools, P. E., Zacks, D., and Yerushalmy, J. (1947). Tuberculosis case finding: a comparison of the effectiveness of various roentgenographic and photofluorographic methods. J. Amer. med. Ass., 133, 359-366.

Bull, J. W., Couch, R. S., Joyce, D., Marshall, J., Potts, D. G., and Shaw, D. A. (1960). Observer variation in intracerebral angiography. Brit.J. Radiol., 33, 165-170.

Dassel, P. M. (1962). Innocuous filling of the intestinal glands of the colon during barium enema (spiculation) simulating organic disease. Radiology, 78, 799-801.

Davies, L. G. (1958). Observer variation in reports on electrocardiograms. Brit. Heart J., 20, 153-161.

Fletcher, C. M. (1952). The clinical diagnosis of pulmonary emphysema: an experimental study. Proc. roy. Soc. Med., 45, 577-584.

Garland, L. H. (1949). Scientific evaluation of diagnostic procedures. Radiology, 52, 309-327.

Poppel, M. H., and Beranbaum, S. L. (1957). The indenture sign in acute exudative colitis. Amer. J. dig. Dis., 2, 382-386.

Stierlin, E. (1912). Zur Röntgendiagnostik der colitis ulcerosa. Z.klin. Med., 75, 486-493. 